\title{
Knowledge and understanding among medical imaging professionals in India during the rapid rise of the covid-19 pandemic
}

\author{
Rahul P Kotian $^{1}$ (D) Disha Faujdar ${ }^{1} \cdot$ Sneha P Kotian ${ }^{2} \cdot$ Brayal D'souza $^{3}$ \\ Received: 17 April 2020 / Accepted: 9 May 2020 / Published online: 25 May 2020 \\ (C) IUPESM and Springer-Verlag GmbH Germany, part of Springer Nature 2020
}

\begin{abstract}
During the first week of March,2020 the surge of coronavirus disease (COVID-19) cases reached all over the globe with more than 100,000 cases. Healthcare national and international authorities have already initiated awareness and lockdown activities. A poor understanding of the disease among medical imaging professionals (MIPs) may result in rapid spread of infection. This study aimed to investigate the knowledge and understanding of MIPs about COVID-19. A cross-sectional, web-based study was conducted among MIPs about COVID- 19 during the fourth week of March 2020. An online sample of MIPs was successfully recruited via the authors' networks in India using data collection tool - write google forms. A self-developed online KAP questionnaire was completed by the participants. The knowledge and understanding questionnaire consisted questions regarding the clinical characteristics and transmission routes of COVID-19. Assessment on practices towards COVID-19 included questions on techniques while imaging against COVID-19 suspected patients. Of 700 participants, a total of 550 MIPs completed the survey (response rate: $78.57 \%$ ); $56.7 \%$ were males, $85.4 .1 \%$ were aged $17-26$ years, and most were undergraduates (77.6\%) and postgraduates (17.1\%). Regarding COVID-19, most of the participants answered correctly (95.5\%) on symptoms, $(84.4 \%)$ time interval for visible symptoms, $(98.0 \%)$ transmission and (44\%) airborne transmission respectively. A significant proportion of MIPs (36.4\%) had poor knowledge about wearing multiple masks as an effective measure against coronavirus infection. Most of the respondents (48.5\%) incorrectly considered X-ray as the reliable method of diagnosis for suspected COVID-19 patients. $44.6 \%$ of the respondents lacked knowledge about the steps involved in hand washing technique which is one of the most important safety practice methods in medical imaging to prevent spread of infection. Factors such as age and occupation were associated with inadequate knowledge and poor perception of COVID-19. As the current global threat of COVID-19 continues to emerge, it is crucial and critical to improve the knowledge and understanding of MIPs. Educational videos and live webinars are urgently needed to reach MIPs and further detailed studies are the need of the hour.
\end{abstract}

Keywords Knowledge $\cdot$ Attitude $\cdot$ Practice $\cdot$ COVID-19 $\cdot$ India

This article is part of the COVID-19 Health Technology: Design,

Regulation, Management, Assessment

Electronic supplementary material The online version of this article (https://doi.org/10.1007/s12553-020-00437-2) contains supplementary material, which is available to authorized users.

Rahul P Kotian

kotian.rahu18@gmail.com

Disha Faujdar

disha.faujdar@gmail.com

Sneha P Kotian

snehakot@gmail.com

Brayal D'souza

brayaldsouza@manipal.edu
1 Department of Medical Imaging Technology, College of Allied Health Sciences, Srinivas University, Mukka Karnataka, India

2 Department of Community Medicine, MGM Medical College, Navi Mumbai, India

3 Department of Health Innovation, PSPH, Manipal Academy of Higher Education, Manipal, India 


\section{Background}

Coronavirus disease 2019 (abbreviated "COVID- 19") is a life threatening respiratory disease caused by a novel coronavirus and was first detected in December 2019 in China. The disease is considered highly infectious, with clinical symptoms of fever, dry cough, fatigue, dyspnea and myalgia. In India, approximately 1834 patients were tested positive with COVID-19 by the first week of April, 2020 and 41 deaths reported. Clinical data have shown that the overall death rate of COVID-19 is between $0.2 \%$ to $1.6 \%$ in India, much lower than those of SARS $(9.5 \%)$, MERS (34.4\%), and H7N9 $(39.0 \%)(1-4)$.

The COVID-19 was declared pandemic on March 11th 2020 by WHO and by then had inflicted 114 countries and caused 4291 deaths. The World Health Organization immediately responded to this serious situation and declared it as a public health emergency of international concern on January 30 and requested for collaborative efforts of all countries in the world to prevent the rapid spread of COVID-19 (5). India, has also been seriously hit by the COVID-19 pandemic. Some unprecedented measures have been adopted by our Prime Minister Shri Narendra Modi to control the COVID-19 transmission in India including complete lockdown with stay at home policy in the country from March 23rd, 2020 till April 14, 2020.

The fierce battle against COVID-19 is still a matter of major concern in India. To guarantee the final success, adherence to these control measures by the Medical Imaging healthcare providers are essential, which is largely affected by their knowledge, attitudes, and practices (KAP) towards COVID19 in accordance with KAP theory because imaging diagnosis is the second step for COVID-19 confirmation after blood test. Lessons learned from the SARS outbreak in 2003 suggest that knowledge and attitudes towards infectious diseases is of utmost importance which can further complicate attempts to prevent the spread of the disease (6).

To facilitate outbreak management of COVID-19 in India, there is an urgent need to understand that the medical imaging professionals (MIPs) awareness of COVID-19 at this critical moment. In this study, we investigated the KAP towards COVID-19 of MIPs during the rapid rise period of the COVID-19 outbreak.

\section{Methods}

\subsection{Participants}

An online cross-sectional survey during the rapid rise period of the COVID-19 outbreak was used to assess the knowledge and understanding among MIPs on COVID-19 in India between March 31, 2020 to April 05, 2020, the second week after the national lockdown. This was an online survey as it was not convenient and feasible to do a community-based national sampling survey due to the global emergency.

The questionnaire were sent to 700 participants via Google forms, the identity of the contributors were kept anonymous. The minimum eligibility to participate in the survey was that the respondents were from the medical imaging fraternity. The questionnaire used in the present study was formed by referring information about COVID- 19 on website of World Health Organization, Centre for Disease Control and Prevention (CDC), expert discussion and their opinion. The questionnaire was then given to five experts in the field of medical imaging, public health and community medicine with more than five years of experience for content validity.

\subsection{Ethical considerations}

Confidentiality of the study participants' information was maintained throughout the study by making the participants' information anonymous. An informed consent was obtained from each participant prior to participation.

\subsection{Data collection}

The data collection was done between 31st March to 5th April 2020. The questionnaire was administered after by

Table 1 Demographic characteristics of participants and knowledge score of COVID-19 by demographic variables

\begin{tabular}{llc}
\hline Characteristics & Number of participants \% \\
\hline Gender & & $312(56.7)$ \\
& Male & $238(43.3)$ \\
& Female & \\
Age groups & & $471(85.6)$ \\
& $17-26$ & $54(9.8)$ \\
& $27-36$ & $11(2)$ \\
& $37-46$ & $14(2.6)$ \\
& $47-56$ & \\
Education & & $4(0.7)$ \\
& PhD & $94(17.1)$ \\
& Postgraduate & $427(77.6)$ \\
& Undergraduate & $21(3.8)$ \\
& Diploma & $4(0.8)$ \\
& Distance education & $320(58.2)$ \\
Occupation & & $64(11.6)$ \\
& Student & $126(22.9)$ \\
& Intern & $35(6.4)$ \\
& Technologist & $5(0.9)$ \\
& Teaching Staff & \\
& Administrator & \\
\hline
\end{tabular}


Government of India had declared the lockdown. The details of the study was provided to the participants before beginning the survey. The questionnaire was administered in English language.

\subsection{Measures/ content of the study tool}

The questionnaire consisted of 15 items to assess their knowledge and attitudes of COVID-19 which took approximately 3 min to complete. The questionnaire consisted of two parts namely: demographics and KAP. Demographic variables included age, gender, education and occupation. The overall questionnaire had 15 questions (Table 1): regarding clinical presentations, regarding transmission routes and regarding prevention and control during Medical Imaging procedures of COVID-19. Attitudes towards COVID-19 were assessed through questions about training and safe use of personal protective equipment. The assessment of practices were through questions on various imaging procedures. These questions were answered on a multiple choice option, true/false basis with an additional "Not so sure" option.

\subsection{Data analysis}

The data analysis was done using descriptive statistics of mean \& SD for continuous variables and for disc rete variables frequency and percentage was used. The responses obtained in the study was analysed using SPSS 16.0.

\section{Results}

A total of 700 MIPs were requested to participate in the study by sending questionnaire through e-mails and social media whatsapp application and 550 responded (response rate $78.57 \%$ ). Majority of them $(77.6 \%)$ had undergraduate qualification in medical imaging, $17.1 \%$ had postgraduate qualification in medical imaging, $3.8 \%$ had diploma in medical imaging, $0.7 \%$ had distance education in medical imaging and $0.7 \%$ had $\mathrm{PhD}$ in medical imaging. A total of 550 participants completed the survey questionnaire. Among this final sample, the average age was 23.39 years (standard deviation [SD]: 6.42 , $(56.7 \%)$ were men and $(43.3 \%)$ were women. Other demographic characteristics are shown in Table 1.

Most of the respondents answered correctly on (95.5\%) symptoms, (84.4\%) time interval for visible symptoms, $(98.0 \%)$ transmission however it was low for airborne transmission respectively (44\%). Most of the respondents $(36.4 \%)$ wrongly considered wearing multiple masks as an effective measure against coronavirus infection. The ideal distance to be maintained from a person infected with COVID-19 was rightly answered by only $(43.5 \%)$ of the respondents. When it came to steps involved in handwashing, it was observed that only $56.4 \%$ respondents were fully aware about this technique. Most of the respondents $(48.5 \%)$ incorrectly considered $\mathrm{X}$-ray as the reliable method of diagnosis for suspected COVID-19 patients. About (81.6\%) of the respondents were also aware about infection control at the radiology department after imaging suspected COVID-19 patients. The most preferred investigation of choice for COVID-19 suspected patients as portable x-ray was answered only by $(29.5 \%)$ MIPs. Majority of respondents $(50.7 \%)$ considered computed tomography as the preferred investigation for COVID-19 suspected patients. While analysing questions pertaining to attitude of medical imaging professionals, it was found that in majority $(46.5 \%)$ underwent training for the safe use of personal protective equipment (PPE). The questions regarding practices followed by the imaging professionals on considering air-exchange rate in imaging rooms, after scanning a suspected COVID-19 patient was unclear with respondents having mixed responses (15.5\%) $15 \mathrm{~min}$, (28.4\%) $30 \mathrm{~min}, 1$ (28.5\%) and 2 (27.6\%) hour respectively. The right answer was one hour of air exchange after imaging suspected COVID-19 patients. While analysing question pertaining to awareness about two radiographers using the 'one clean, one in contact with patient system $(47.3 \%)$ were aware about this technique. Interestingly, it was observed that (57.5\%) respondents were aware about the use of lead gown before wearing the PPE. Lastly, (91.5\%) respondents were very well aware about the necessary steps to limit COVID-19 transmission. The detailed summary of the results are depicted in Table 2-3.

\section{Discussion}

To the best of our knowledge, this is the first study in India examining the KAP towards COVID-19 among MIPs. Currently, COVID-19 is a topic of global discussion in the media and among the public, especially among MIPs and patients. With the current case surge of COVID-19 transmission raising tensions for everyone, including health officials and National health systems, an important question arises regarding how to disseminate information to help frontline MIPs in times of public health crisis. For this reason, we investigated their knowledge and understanding on the precautions and control of COVID-19 during a global epidemic.

The finding of a high correct rate of COVID-19 knowledge in MIPs was unexpected, because this epidemiological survey was conducted during the very early stage-II of the pandemic. We consider that this is primarily due to the sample characteristics: $77.6 \%$ of the study respondents held an bachelor's degree and $17.1 \%$ of the respondents held a postgraduate degree. Because of the serious situation of the pandemic and the overwhelming news reports on this public health emergency, this population would actively learn knowledge of this infectious disease from various TV and news channels and the official 
Table 2 Responses of medical imaging professionals to knowledge; attitude and practice questionnaire on COVID-19

\begin{tabular}{|c|c|c|}
\hline $\begin{array}{l}\text { Question } \\
\text { no }\end{array}$ & Questions (Correct rate, $\%$ of the total sample) & Options (\%) \\
\hline 1 & $\begin{array}{l}\text { Most common symptoms of Coronavirus (COVID -19) are fever, } \\
\text { tiredness \& dry cough.* }(95.5 \%)\end{array}$ & True, false $(3.5 \%)$, not sure $(1.1 \%)$ \\
\hline 2 & $\begin{array}{l}\text { The coronavirus infection can be transmitted through small droplets } \\
\text { from nose or mouth of infected person.* }(98 \%)\end{array}$ & True, false $(1.1 \%)$, not sure $(0.9 \%)$ \\
\hline 3 & $\begin{array}{l}\text { Does the coronavirus infection spread through airborne transmission?* } \\
(44 \%)\end{array}$ & True $(36.5 \%)$, false, not sure $(19.5 \%)$ \\
\hline 4 & $\begin{array}{l}\text { Wearing multiple masks is effective against coronavirus infection? * } \\
(25.5 \%)\end{array}$ & Yes $(36.4 \%)$, no, maybe $(38.2 \%)$ \\
\hline 5 & $\begin{array}{l}\text { Ideal distance to be maintained from a person infected with COVID-19 } \\
\text { is? } *(43.5 \%)\end{array}$ & $1(23.8 \%), 3,6(27 \%) \& 10(5.6 \%)$ feet \\
\hline 6 & $\begin{array}{l}\text { The symptoms of COVID-19 in an infected person are visible after? * } \\
(84.4 \%)\end{array}$ & $0-2(1.1 \%), 2-14,15-20(12.5 \%) \&$ beyond $(2 \%) 20$ days \\
\hline 7 & How many steps are involved in hand washing technique?* (56.4\%) & $2(1.5 \%), 4(10 \%), 6 \& 8(32.2 \%)$ \\
\hline 8 & $\begin{array}{l}\text { Can x-ray be regarded as the reliable method of diagnosis for suspected } \\
\text { COVID-19 patients? } *(25.3 \%)\end{array}$ & Yes $(48.5 \%)$, no, not sure $(26.2 \%)$ \\
\hline 9 & $\begin{array}{l}\text { Which among the following is important for infection control in } \\
\text { radiology department after imaging suspected COVID-19 patients.* } \\
(81.6 \%)\end{array}$ & $\begin{array}{l}\text { Environmental cleaning (6.5\%), decontamination of room }(9.8 \%) \text {, } \\
\text { maintaining airflow }(2 \%) \& \text { all of the above }\end{array}$ \\
\hline 10 & $\begin{array}{l}\text { Which of these is the preferred modality in order to screen a patient for } \\
\text { COVID- } 19 ? *(29.5 \%)\end{array}$ & $\begin{array}{l}\text { CT }(50.7 \%) \text {, ultrasound }(2.9 \%) \text {, portable x-ray machine \& x-ray } \\
\quad(16.9 \%)\end{array}$ \\
\hline 11 & $\begin{array}{l}\text { Amidst this COVID-19 pandemic, have you undergone the training for } \\
\text { the safe use of personal protective equipment (PPE).** }\end{array}$ & Yes $(46.5 \%)$, no $(41.5 \%)$, maybe $(12 \%)$ \\
\hline 12 & $\begin{array}{l}\text { Considering the Air-Exchange rate in rooms, after scanning a suspected } \\
\text { COVID-19 patient, the radiographic suite may need to be completely } \\
\text { avoided for* }(28.5 \%)\end{array}$ & $15 \min (15.5 \%), 30 \min (28.4 \%), 1 \mathrm{~h} \& 2 \mathrm{~h}(27.6 \%)$ \\
\hline 13 & $\begin{array}{l}\text { Are you aware of the two radiographers using the 'one clean, one in } \\
\text { contact with patient' system? } * *\end{array}$ & Yes $(47.3 \%)$, no (28.5\%), not sure (24.2) \\
\hline 14 & When should the Lead gown be worn by the radiographer? $*(57.5 \%)$ & $\begin{array}{l}\text { Before the radiographer wears the PPE, after wearing the PPE } \\
(26.9 \%) \& \text { not sure }(15.6 \%)\end{array}$ \\
\hline 15 & The necessary steps to limit COVID-19 transmission involves* (91.5\%) & $\begin{array}{l}\text { Cleaning and draping the x-ray machine }(2.2 \%) \text {, cleaning the } \\
\text { cassette }(5.8 \%) \text {, cleaning the anatomical markers }(0.5 \%) \& \text { all } \\
\text { of the above }\end{array}$ \\
\hline
\end{tabular}

website of the National Health Commission of India. The levels of education and COVID-19 knowledge scores supports this speculation. However when it came to questions pertaining to practices during medical imaging procedures of suspected COVID-19 patients, most of the MIPs have insufficient knowledge about dealing with COVID-19 suspected patients and managing the radiology imaging room.

Interestingly, as most of the respondents answered correctly about the symptoms of COVID-19, majority of the respondents $44 \%$ answered incorrectly about the airborne transmission of COVID-19 virus. The coronavirus infection can be transmitted through small droplets from nose or mouth of an infected COVID-19 individual and this might have caused confusion among the respondents about its airborne transmission route. The findings about lack of knowledge about steps involved in hand washing technique was a vital finding of this study and needs to be corrected immediately if we want to contain the spread of COVID-19 infection in India as MIPs are the first line healthcare providers.

$44.6 \%$ of the respondents lacked knowledge about the steps involved in hand washing technique which is one of the most important safety practice methods in medical imaging to prevent spread of infection. Blood test is the first and most reliable method of diagnosis for suspected COVID-19 patients. However, x-ray investigation can only be used as a supplementary measure for confirming COVID-19. Majority of the respondents $48.5 \%$ wrongly answered that x-ray can be regarded as the reliable method of diagnosis for suspected COVID-19 patients. The preferred imaging modality of choice to screen a suspected COVID-19 patient is portable $\mathrm{x}$-ray because it is easy to follow infection control measures and the radiology imaging room will also not be contaminated. It is also easy to disinfect and clean the portable x-ray unit and the isolated room where the imaging procedure was done. However, most of the respondents $50.7 \%$ considered computed tomography (CT) scan as the preferred modality in order to screen a suspected patient for COVID-19. CT may provide the following vital findings in COVID-19 positive cases: ground glass opacities in the lungs, air space consolidation, crazy paving appearance and broncho-vascular thickening in the lesion (7-10). Hence, we presume that the respondents might have gone through these studies and hence they considered 
Table 3 Knowledge about Novel coronavirus (COVID-19) among MIPs $(N=550)$

Sr.no Questions (Correct rate, \% of the total sample)

$\begin{array}{lllll}\mathrm{PhD} & \text { Postgraduates } & \text { Undergraduates } & \text { Diploma } \\ \mathrm{n}=4 & n=94 & n=427 & n=21 & \begin{array}{l}\text { Distance } \\ \text { education } \\ \end{array} \\ & & & n=4\end{array}$

1 Most common symptoms of Coronavirus (COVID -19) are fever, tiredness \& dry $4 \quad 93$ cough.*(95.5\%)

2 The coronavirus infection can be transmitted through small droplets from nose or $4 \quad 95$ mouth of infected person.* $(98 \%)$

4 Wearing multiple masks is effective against coronavirus infection? $*(25.5 \%) \quad 3 \quad 25$

$5 \quad$ Ideal distance to be maintained from a person infected with COVID-19 is? * $\quad 2 \quad 49$ $(43.5 \%)$

6 The symptoms of COVID-19 in an infected person are visible after? $*(84.4 \%) \quad 4 \quad 90$

7 How many steps are involved in hand washing technique?* (56.4\%) $\quad 4 \quad 60$

8 Can $\mathrm{x}$-ray be regarded as the reliable method of diagnosis for suspected COVID-19 patients? * $(25.3 \%)$

9 Which among the following is important for infection control in radiology department after imaging suspected COVID-19 patients.* (81.6\%)

10 Which of these is the preferred modality in order to screen a patient for COVID-19? $*(29.5 \%)$

11 Considering the Air-Exchange rate in rooms, after scanning a suspected $\quad \begin{array}{lll}1 & 48\end{array}$ COVID-19 patient, the radiographic suite may need to be completely avoided for* $(28.5 \%)$

12 Are you aware of the two radiographers using the 'one clean, one in contact with $2 \quad 23$ patient' system? $* *$

13 When should the Lead gown be worn by the radiographer? * $(57.5 \%)$

14 The necessary steps to limit COVID-19 transmission involves* (91.5\%)

$4 \quad 55$

404

$204-4$

415

$415 \quad 21 \quad 4$

105

105
175

$7 \quad 0$

(175

357

130

60

192

112

$10-1$

40

1

$8 \quad 0$

114

CT to be the preferred modality of choice for suspected COVID-19 patients. The participants of the current study showed fair knowledge about general precautions about COVID-19 but showed poor knowledge about practices to be followed while dealing with COVID-19 suspected patients. Majority of the respondents $71.6 \%$ were unaware about airexchange rate in rooms, after scanning a suspected COVID-19 patient and avoiding the radiographic suite for one hour. And lastly, among the MIPs $52.7 \%$ were also unaware about two radiographers using the 'one clean, one in contact with patient' system while imaging suspected COVID-19 patient.

The strength of this study lies in its large sample recruited during a critical period, the early stage of the COVID-19 outbreak in a given Allied health speciality. Given the significant associations between these demographic variables and KAP towards COVID-19 revealed in this study, we may have overestimated knowledge and rates of preventive practices and underestimated rates of positive attitudes towards COVID-19 of MIPs. The present study was conducted in a standardized manner. The authors used a questionnaire which was developed through stages of item development, content validation and test-retest reliability. However, the study had few inadvertent limitations. To improve response rate, the number of questions were kept limited. Hence, the knowledge, attitude and practice of the MIPs cannot be fully determined. In addition, the data presented in this study are selfreported and partly dependent on the participants' honesty and

recall ability; thus, they may be subject to recall bias. There may be a responder bias as only respondents who have better knowledge of COVID-19 may have responded.

Finally, due to the four-week closure of higher educational institutions in India during the COVID-19 outbreak, the institutional review board was not approached. Despite these limitations, the present study provides vital information about the knowledge and understanding of medical imaging professionals during the rapid rise period of COVID-19.

\section{Conclusion}

In summary, our findings suggest that MIPs, have poor knowledge, attitudes, and appropriate practices towards COVID-19 during the rapid rise period of the COVID-19 outbreak. However, the MIPs had good knowledge about the symptoms and general awareness on COVID-19.

Hopefully, under the combined efforts of Indian authorities and all Indian residents, India surely will win the battle against COVID-19 in the near future.

Acknowledgements The authors thank all the medical imaging professionals involved in this study for their cooperation and support.

Availability of data and material The datasets used and/or analysed during the current study is made available by the corresponding author and attached in the supplementary files. 
Authors' contributions RK conceptualized the study. DF and SPK have given inputs in study design. RK and DF collected the data. RK analysed the data and wrote the first draft of manuscript and all co- authors contributed in critical review of data analysis and manuscript writing. RK will act as guarantor for this paper.

\section{Compliance with ethical standards}

Ethics approval and consent to participate The study protocol followed was reviewed and approved by the Research Committee of Srinivas University telephonically and approved online. The consent to participate approval was also taken.

\section{Ehical approval reference number Not applicable.}

Consent for publication A detailed explanation about the study was given by the principal investigator after which they provided consent for publication. All the patients included in this research gave written informed consent to publish the data contained within this study.

Competing interests The authors declare that they have no competing interests in this study.

Conflict of interest The authors declare that they have no competing of interests.

\section{References}

1. N Chen, M Zhou, X Dong, J Qu, F Gong, Y Han, et al. Epidemiological and clinical characteristics of 99 cases of 2019 novel coronavirus pneumonia in Wuhan, China: a descriptive study. Lancet (London, England) [Internet]. 2020 Feb 15 [cited 2020 Apr 6];395(10223):507-13. Available from: https:// linkinghub.elsevier.com/retrieve/pii/S0140673620302117

2. Munster VJ, Koopmans M, van Doremalen N, van Riel D, de Wit E. A Novel Coronavirus Emerging in China - Key Questions for Impact Assessment. N Engl J Med [Internet]. 2020 Feb 20 [cited 2020 Apr 6];382(8):692-4. Available from: http://www.nejm.org/ doi/10.1056/NEJMp2000929

3. Zhong B-L, Luo W, Li H-M, Zhang Q-Q, Liu X-G, Li W-T, et al. Knowledge, attitudes, and practices towards COVID-19 among
Chinese residents during the rapid rise period of the COVID-19 outbreak: a quick online cross-sectional survey. Int J Biol Sci [Internet]. 2020;16(10):1745-52 Available from: http://www.ijbs. com//creativecommons.org/licenses/by/4.0/\%0Ahttp://www.ijbs. com/v16p1745.htm\%0Ahttps://www.ijbs.com/v16p1745.htm.

4. Novel Coronavirus Pneumonia Emergency Response Epidemiology Team. [The epidemiological characteristics of an outbreak of 2019 novel coronavirus diseases (COVID-19) in China]. Zhonghua Liu Xing Bing Xue Za Zhi [Internet]. 2020 Feb 17 [cited 2020 Apr 6];41(2):145-51. Available from: http:// www.ncbi.nlm.nih.gov/pubmed/32064853.

5. I. Fahmi \#Covid19 Coronavirus Disease 2019. DroneEmprit [Internet]. 2020;2019(April):1-19. Available from: https://pers. droneemprit.id/covid19/

6. B Person, F Sy, K Holton, B Govert, A Liang, National Center for Inectious Diseases/SARS Community Outreach Team B, et al. Fear and stigma: the epidemic within the SARS outbreak. Emerg Infect Dis [Internet]. 2004 Feb [cited 2020 Apr 6];10(2):358-63. Available from: http://wwwnc.cdc.gov/eid/article/10/2/03-0750 article.htm

7. H Shi, X Han, N Jiang, Y Cao, O Alwalid, J Gu, et al. Radiological findings from 81 patients with COVID-19 pneumonia in Wuhan, China: a descriptive study. Lancet Infect Dis [Internet]. $2020 \mathrm{Apr}$ [cited 2020 Apr 7];20(4):425-34. Available from: http://www.ncbi. nlm.nih.gov/pubmed/32105637.

8. F Pan, T Ye, P Sun, S Gui, B Liang, L Li, et al. Time Course of Lung Changes On Chest CT During Recovery From 2019 Novel Coronavirus (COVID-19) Pneumonia. Radiology [Internet]. 2020 Feb 13 [cited 2020 Apr 7];200370. Available from: http://pubs. rsna.org/doi/10.1148/radiol.2020200370

9. D Wang, B Hu, C Hu, F Zhu, X Liu, J Zhang, et al. Clinical Characteristics of 138 Hospitalized Patients With 2019 Novel Coronavirus-Infected Pneumonia in Wuhan, China. JAMA [Internet]. $2020 \mathrm{Feb} 7$ [cited $2020 \mathrm{Apr}$ 7];323(11):1061. Available from: https://jamanetwork.com/journals/jama/fullarticle/ 2761044

10. EYP Lee, M-Y Ng, Khong P-L. COVID-19 pneumonia: what has CT taught us? Lancet Infect Dis [Internet]. 2020 Apr [cited 2020 Apr 7];20(4):384-5. Available from: https://inkinghub.elsevier. com/retrieve/pii/S1473309920301341

Publisher's note Springer Nature remains neutral with regard to jurisdictional claims in published maps and institutional affiliations. 